\title{
Geo-environmental problem of snow avalanche defensive structures in mudstone zones, Niigata Prefecture, Japan
}

\author{
K. Aoyama' ${ }^{\text {, * P. Bhattarai }}{ }^{2}$, M. Fukuda ${ }^{3}$, J. Oku ${ }^{4}$, and T. Sakai ${ }^{5}$ \\ 'Research Institute for Hazards in Snowy Areas, Niigata University, Niigata, Japan \\ ${ }^{2}$ Graduate School of Science and Technology, Niigata University, Niigata, Japan \\ (*Corresponding author, e-mail: pankaj@niigata.u ac.jp) \\ ${ }^{3}$ Nagaoka Technical College, Nagaoka, Japan \\ ${ }^{4}$ Japan Highway Corporation, Tokyo, Japan \\ ${ }^{5}$ Niigata Prefectural Government, Niigata, Japan
}

\begin{abstract}
Fence-type defensive structures are very common on highway hillsides in Japan. They are constructed to protect the highway mainly from snow avalanche. Initially, these structures behave well. However, as the time lapses, the foundation of these well designed structures weakens and collapses. The situation is further aggravated by the static load of accumulated thick snow cover behind them. As mudstone is the dominant rock type in the Niigata Prefecture, it is a challenging task for geotechnical engineers to cope with such a severe geo-environmental problem.
\end{abstract}

Although the mudstone exhibits a high strength while it is dry and fresh, it becomes quite unstable after sometime. When it comes in contact with water and atmosphere repeatedly, it starts weathering. Consequently, its shear strength is reduced and cannot resist the imposed shear stress and moment, and ultimately fails.

For the laboratory investigation, mudstone blocks of various sizes were collected from the two typical mudstone areas: the Matsunoyama area and Nagaoka area in the Niigata Prefecture. These samples were submerged and then dried alternately for several cycles. The particle size analysis of the weathered material showed that the proportion of fine particles increased with the degree of weathering. The laboratory tests of these samples exhibited a decrease in shear strength with an increasing degree of saturation. The periodic swelling and contraction of the clay fraction leads to volume change of foundation inducing its further weathering.

\section{INTRODUCTION}

Cold and snowy regions of Japan account for more than $60 \%$ of its total area of 380,000 square kilometers. Snowfalls and snow avalanches are common in these regions and create severe problems in regular traffic movements and, to some extent, destabilize the socio-economic activities. To stabilize and improve the living conditions and socio-economic activities in these regions, the most important thing is securing road traffic in winter. Fence type defensive structures are generally constructed at the hillside along the road in these regions to retain snow avalanche during heavy snowing period. These structures are generally made of steel with solid concrete foundation.

In the past, these structures were built in large numbers by considering geological aspects only, without due consideration of geo-technical aspects. In the snowing period, sometimes the structures tend to deform due to heavy static snow load. That deformation creates a small gap between the foundation and the slope of the hill. Through this gap snow-melt water and rainwater enter the foundation and starts slaking of underneath mudstone. In addition, the seepage water freezes at the night resulting an increment of volume that further helps to widen the gap. This action of freezing and thawing accelerates the disintegration process of mudstone. Also during construction, the deep excavation of foundation disturbs the environment and the embedded mudstone comes in contact with the atmosphere and gradually slakes (Aoyama et al. 1980). Consequently, shear strength is reduced and the structure fails to resist the imposed shear stresses and moments and ultimately fails (Fig. 1).

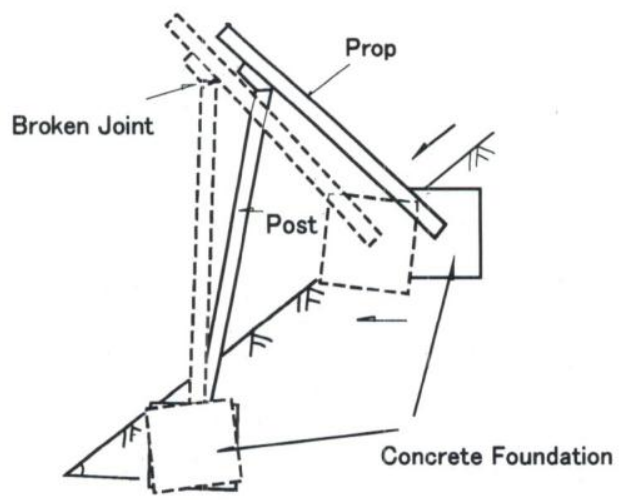

Fig. 1: Deformation of defensive structures. 
This research includes mainly investigation of foundation of snow avalanche defensive structures in mudstone areas and tries to find the weakening mechanism of foundation. It describes the simulation of slaking activities in the laboratory and compares the slaking activities of mudstone of various areas. It also attempts to assess the impact of slaking on other soil properties.

\section{STUDY AREA}

Most of the snow avalanche defensive structures were found collapsed in Nagaoka and Matsunoyama areas of the Niigata prefecture (Fig. 2). The first study area lies in Nigorisawa district, Nagaoka city. The general slope of the area is about 35 degrees where snow gliding is very high in winter. The area is composed of Shiiya Formation (massive tertiary mudstone with alternate layers of mudstone and sandstone)

The second area lies in Matsunoyama district. The general slope is again about 35 degrees but at some places it is steeper, i.e., up to 40 to 45 degrees. The whole area is formed with Shiiya Formation like previous one.

\section{GEO-TECHNICAL PROPERTIES OF MUDSTONE}

\section{Sampling Area}

Nigorisawa

Undisturbed samples of slaked mudstone or weathered mudstone were collected from the foundation zone of the damaged structures. In order to preserve natural water content, samples were covered with vinyl sheet immediately



Fig. 2: Location map of study area in Niigata Prefecture. after their retrieval. The rocks beneath the damaged foundations were found weathered due to constant action of water and air.

\section{Matsunoyama}

Samples were collected from two different sites P and Q. Sampling procedure adopted in the case of Nigorisawa was also followed here.

\section{Laboratory testing and analysis}

In both cases water contents were measured immediately after the samples reached the laboratory. Then sieve analysis, specific gravity test and consistency tests were conducted on all the samples. The results are shown in Table 1.

\section{Nigorisawa}

According to textural classification, the soil was found to be sandy loam. The total percentage of sand and silt was more than $80 \%$ while the amount of clay was just $16 \%$. In comparison to the samples P and Q of Matsunoyama Area, the consistency index was found high, i.e., 1.66, showing that the soil was hard and stable in that condition. The water content of the sample was found $14.8 \%$, which was very low as compared to those of the other two samples.

\section{Matsunoyama}

Both samples of Matsunoyama area were found to be silty loam according to the textural classification. The percentage of clay in both samples was $21 \%$. The value of $\mathrm{d}_{10}$ was found to be $0.009 \mathrm{~mm}$ and $0.004 \mathrm{~mm}$ for sample $P$ and $\mathrm{Q}$, respectively. The consistency indices of both the samples were very low, i.e., 0.41 and 0.43 , and the measured water contents were $43.8 \%$ and $51.6 \%$, respectively. In this condition both the samples were found to be very weak.

Table 1: Soil properties of study area.

\begin{tabular}{|l|c|c|c|}
\hline \multirow{2}{*}{ Type of properties } & \multirow{2}{*}{ Nigorisawa } & \multicolumn{2}{c|}{ Matsunoyama } \\
\cline { 3 - 4 } & & sample P & sample Q \\
\hline Specific Gravity, G & 2.67 & 2.68 & 2.61 \\
\hline Liquid Limit, LL (\%) & 52.5 & 53.6 & 67.6 \\
\hline Plastic Limit, PL (\%) & 29.7 & 29.5 & 30 \\
\hline Plasticity Index, PI (\%) & 22.7 & 24.1 & 37.6 \\
\hline$D_{60}$ mm & 0.2 & 0.051 & 0.04 \\
\hline$D_{30}$ mm & 0.027 & 0.02 & 0.013 \\
\hline$D_{10}$ mm & 0.002 & 0.009 & 0.004 \\
\hline $\begin{array}{l}\% \\
\text { sieve passing through } 2 \mathrm{~mm}\end{array}$ & 100 & 100 & 100 \\
\hline Sand (\%) & 56.3 & 14.2 & 27 \\
\hline Silt (\%) & 24.5 & 64 & 52 \\
\hline Clay (\%) & 16 & 21 & 21 \\
\hline Natural water content, w (\%) & 14.8 & 43.8 & 51.6 \\
\hline Consistency index & 1.66 & 0.41 & 0.43 \\
\hline Textural classification & Sandy loam & silty clay & Silty clay \\
\hline
\end{tabular}




\section{Direct shear Test}

The samples $\mathrm{P}$ and $\mathrm{Q}$ were tested in direct shear testing machine. The samples were first sieved through the $2 \mathrm{~mm}$ size sieve. The dry density of the samples was taken similar to their in situ values, i.e., $1.3 \mathrm{gm} / \mathrm{cm}^{3}$. The samples were then tested at four different water contents. The result of the tests is shown in Table 2. The relationships of normal stress $(\sigma)$ and shear stress $(\tau)$ of sample P and Q are presented (Fig. 3a and b).

The relation between water content (w), cohesion (c) and frictional angle $(\phi)$ shows that both $\mathrm{c}$ and $\phi$ decrease with an increase in water content (Fig. $4 \mathrm{a}$ and b). However, the decreasing rate of $\phi$ is less than that of $c$. In this case, mineralogical composition and particle size might have played significant role. For example, as smectite has high water absorbing capability than other minerals, degree of saturation for various minerals may vary even if the overall water content is the same. Hence, water content and consistency may vary depending on the mineralogical composition of the sample. The relationship of the degree of saturation with $\mathrm{c}$ and $\phi$ is shown (Fig. 5a and b).

Table 2: Mechanical properties of soil from Matsunoyama area.

\begin{tabular}{|l|c|c|c|c|}
\hline Name of Samples & $\mathbf{w}(\%)$ & $\mathbf{S r}(\%)$ & $\mathbf{c}($ Kpa) & $\boldsymbol{\phi}$ (degree) \\
\hline & 26.3 & 65.9 & 64 & 28.4 \\
\hline Matsunoyama & 30.5 & 77 & 53 & 27.5 \\
\hline Sample P & 33.3 & 85.3 & 43 & 23.3 \\
\hline & 36.7 & 91.6 & 37 & 21.8 \\
\hline & 24.7 & 63.9 & 80 & 20.2 \\
\hline Matsunoyama & 29.9 & 77.6 & 70 & 19.8 \\
\hline Sample Q & 33.3 & 86.9 & 64 & 19.8 \\
\hline & 37.2 & 96.3 & 54 & 17.7 \\
\hline
\end{tabular}

IV: water content, $\mathrm{Sr}$ : degree of saturation, c: cohesion, $\phi$ : angle of internal friction

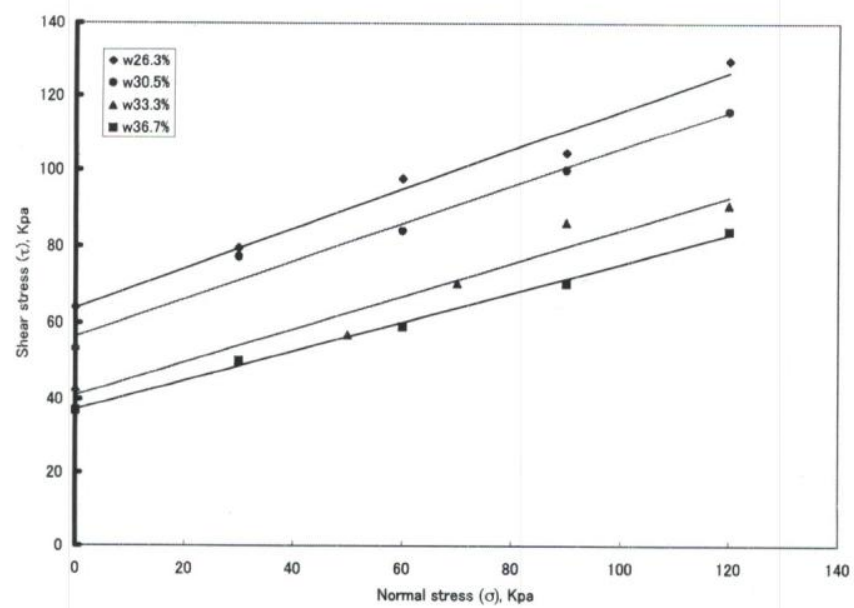

Fig. 3a: Shear failure envelope sample P (Matsunoyama) for various water contents.

\section{Direct shear test with water supplied externally}

To observe the behavior of the soil in saturated condition, an artificial arrangement was made in the laboratory during the shear test. Like previous test, the samples of Nigorisawa and Matsunoyama (P and Q) were sieved through $2 \mathrm{~mm}$ sieve. The dry density was kept similar to their in situ values i.e. $1.3 \mathrm{gm} / \mathrm{cm}^{3}$. The samples were then consolidated for 20 minutes. To make the sample saturate, water was supplied in the specimen for about an hour by arranging external devices. The water head was kept at higher level than shear zone. This was done to confirm that shear zone is in saturation. Then direct shear test was done again as before. The relationship of normal stress $(\sigma)$ and shear stress $(\tau)$ is shown (Fig. 6a, b, and c). The comparative result of the tests was shown on the Table 3 .

It is clear that shear strength depends on the degree of saturation. In the saturated condition, the degree of saturation for Matsunoyama P and Q reached $100 \%$, shear strength suddenly decreased. However, the saturated value of the angle of internal friction $\phi$ was higher than its unsaturated value. Thus from the above tests it is seen that due to snow melt, rainfall or rise in ground water table, the degree of saturation is increased which considerably decreases the shear strength.

\section{Effect of mudstone slaking in failure}

Niigata prefecture is dominated by tertiary mudstones and the Tertiary landslides in Niigata have occurred due to the existence of over consolidated mudstone (Aoyama et al. 1980; Tiwari and Marui 1999). As the water content of the soil increases during snowfall, the shear strength decreases. The effect of slaking in reducing the shear strength has been explained hereunder.

\section{TESTING METHODOLOGY}

Three kilograms of parent mudstone and weathered mudstone (particle size $38.1 \mathrm{~mm}$ to $19.1 \mathrm{~mm}$ ) were collected

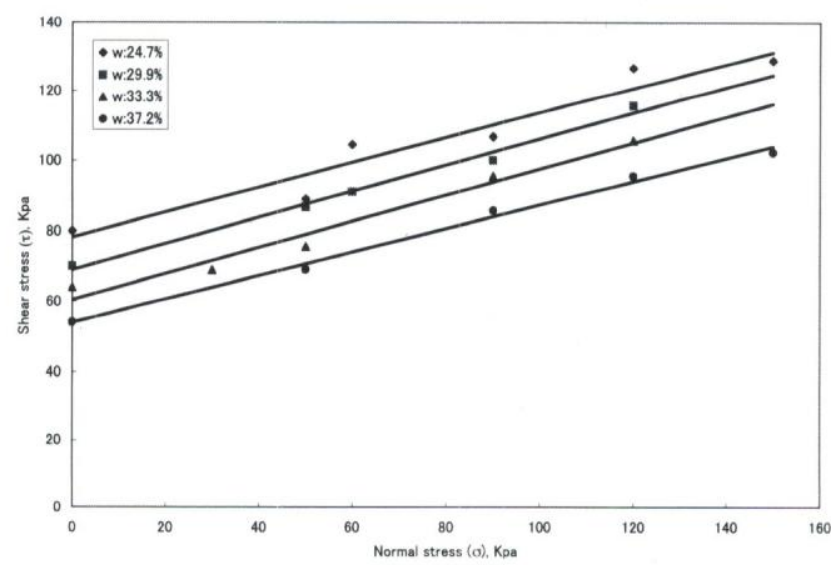

Fig. 3b: Shear failure envelope sample Q (Matsunoyama) for various water contents. 


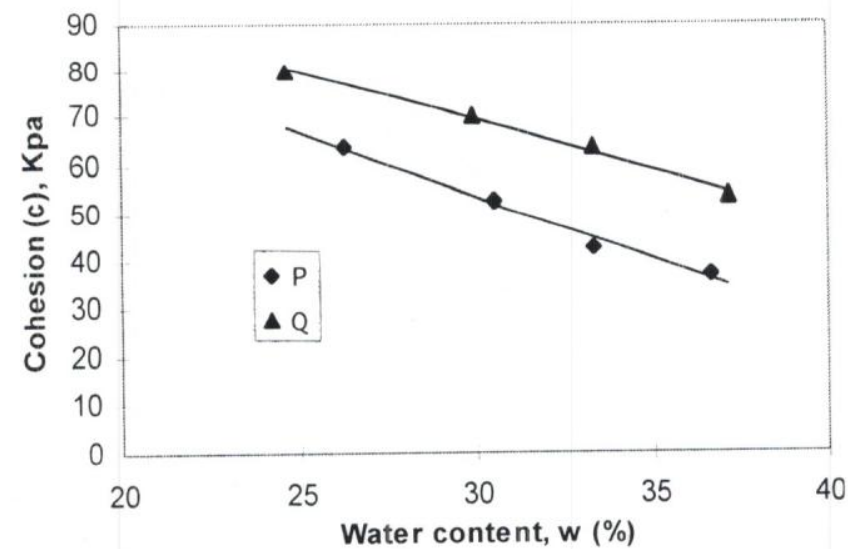

Fig. 4a: Relationship between water content (w) and cohesion (c), Matsunoyama.

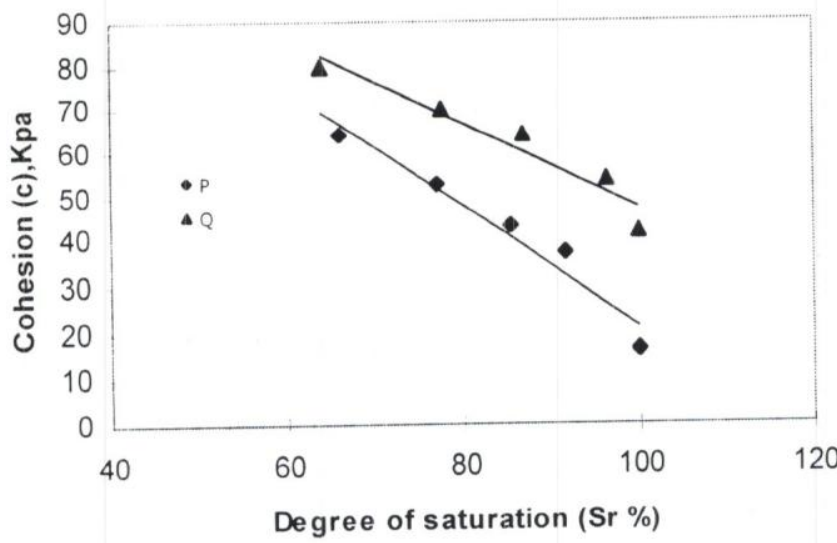

Fig. 5a: Relationship between degree of saturation (Sr) and cohesion (c), Matsunoyama.

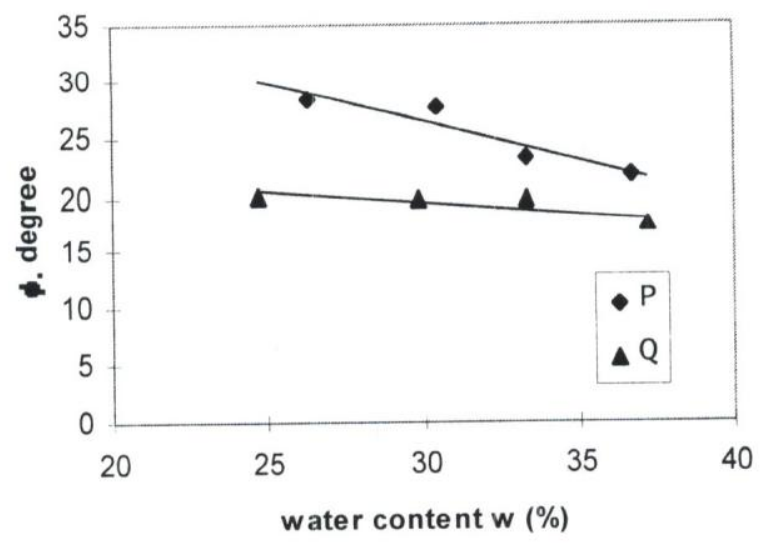

Fig. 4b: Relationship between water content (w) and friction angle $(\phi)$, Matsunoyama.

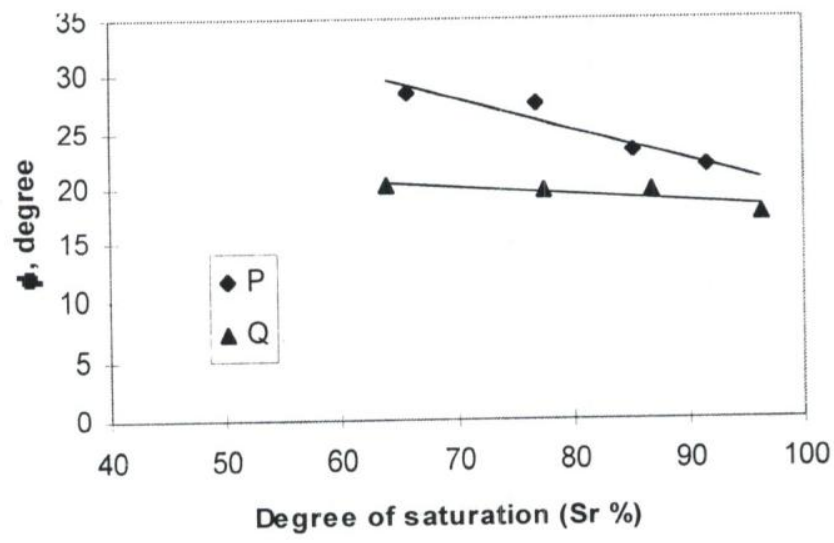

Fig. 5b: Relationship between degree of saturation (Sr) and friction angle $(\phi)$, Matsunoyama.

Table 3: Comparison of shear strength parameters.

\begin{tabular}{|l|l|c|c|c|c|c|}
\hline \multicolumn{1}{|c|}{$\begin{array}{c}\text { Name of } \\
\text { sample }\end{array}$} & \multicolumn{1}{c|}{ condition } & $\begin{array}{c}(\mathbf{w} \%) \\
\text { before test }\end{array}$ & $\begin{array}{c}(\mathbf{w} \%) \text { after } \\
\text { test }\end{array}$ & $\begin{array}{c}\text { (Sr\%) after } \\
\text { test }\end{array}$ & c (Kpa) & $\boldsymbol{\phi}(\mathbf{d e g r e e )}$ \\
\hline Matsunoyama & unsaturated & 30.50 & 30.50 & 77.00 & 53 & 27.5 \\
\hline Sample P & saturated & 30.10 & 40.20 & 100 & 16 & 30.1 \\
\hline Matsunoyama & unsaturated & 29.90 & 29.90 & 77.60 & 70 & 19.8 \\
\hline Sample Q & saturated & 29.80 & 39.10 & 100.00 & 42 & 25.6 \\
\hline Nigorisawa & unsaturated & 30.20 & 30.20 & 75.30 & 45 & 31 \\
\hline & saturated & 30.20 & 37.10 & 92.30 & 15 & 35 \\
\hline
\end{tabular}

w: water content, Sr: degree of saturation, c: cohesion, $\phi$ : angle of internal friction

from study area in Nigorisawa and Matsunoyama. Out of which 10 samples, 5 each for both areas were prepared for testing. The samples were then put in a tray and dried at $110^{\circ} \mathrm{C}$ for 24 hours. Then the samples were allowed to cool down to room temperature and then submerged in water for 24 hours. This completed the first cycle. This process was repeated for 10 cycles in all the samples. Particle size analysis of the disintegrated materials has been done for $1^{\text {st }}, 2^{\text {nd }}, 3^{\text {rd }}, 5^{\text {th }}, 7^{\text {th }}$ and the $10^{\text {th }}$ cycle using $38.1,25.4,19.1,9.52,4.76,2.00,0.84,0.42,0.105,0.074 \mathrm{~mm}$ sieves. Result of one each sample of both areas is shown (Fig.7a,7b). 
Geo-environmental problem of snow avalanche defensive structures in mudstone zones, Japan

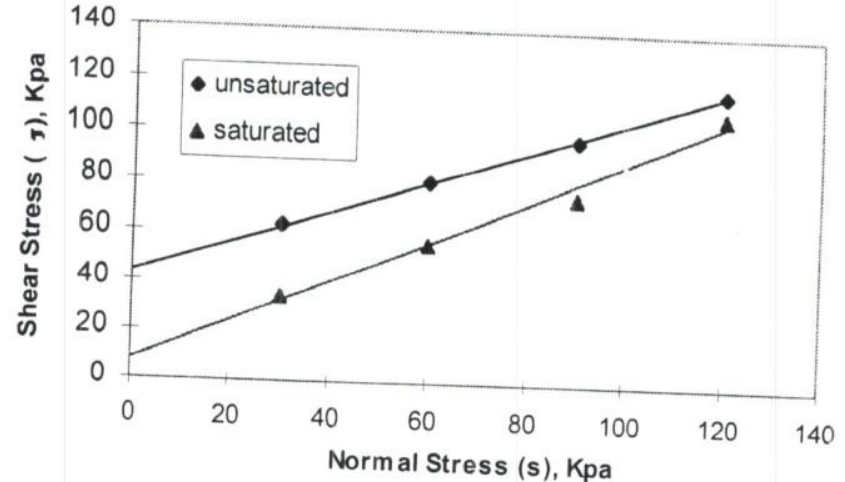

Fig. 6a: Shear failure envelope representing saturated and unsaturated conditions, Nigorisawa.

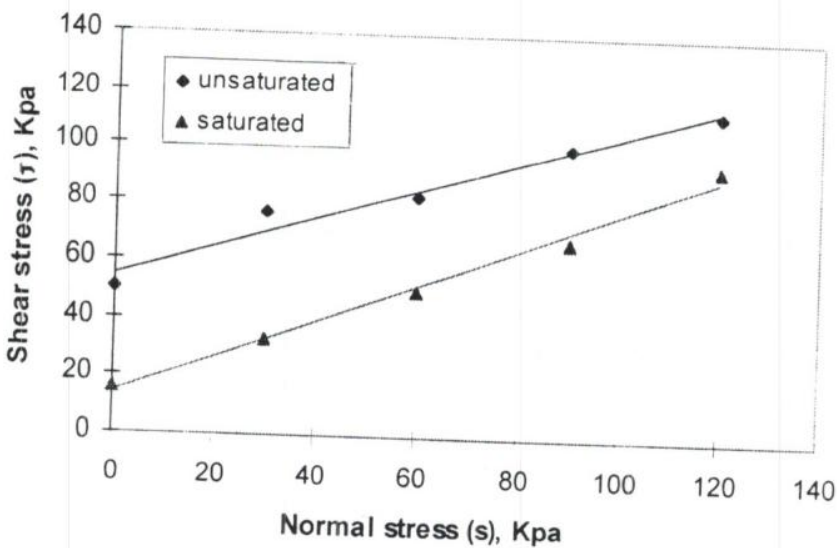

Fig 6c: Shear failure envelope representing saturated and unsaturated conditions, Sample P, Matsunoyama area.

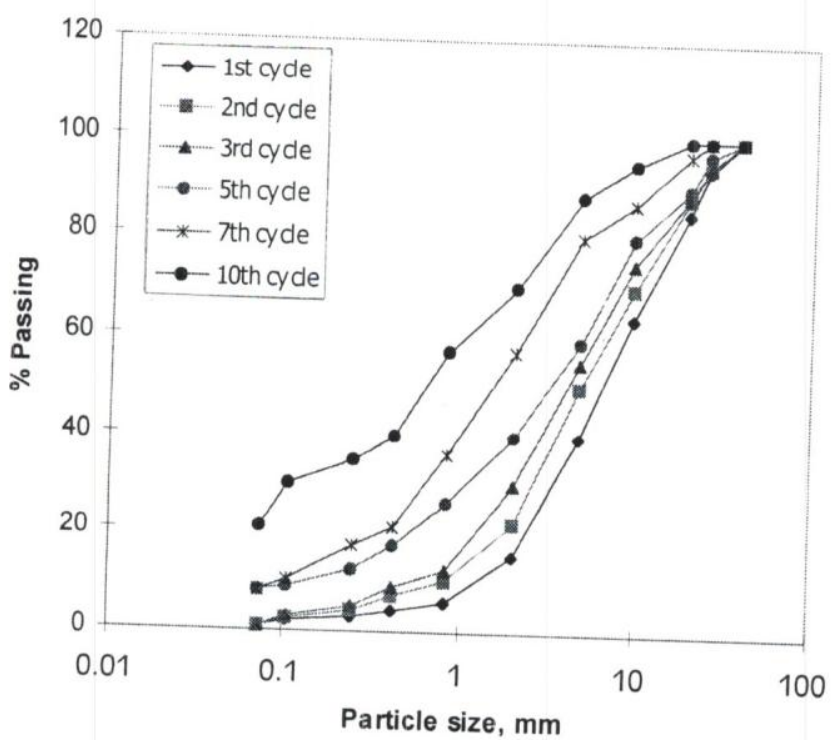

Fig. 7b: Particle size distribution curves for different slaking cycles, Matsunoyama.

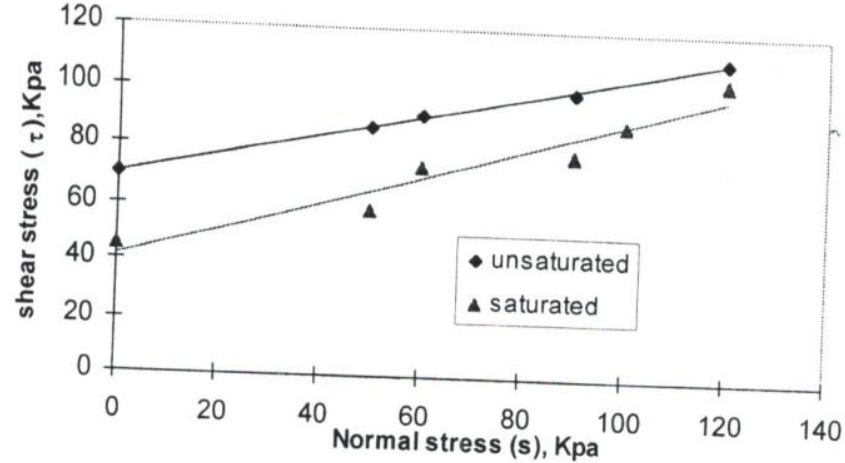

Fig 6b: Shear failure envelope representing saturated and unsaturated conditions for sample $Q$, Matsunoyama area.

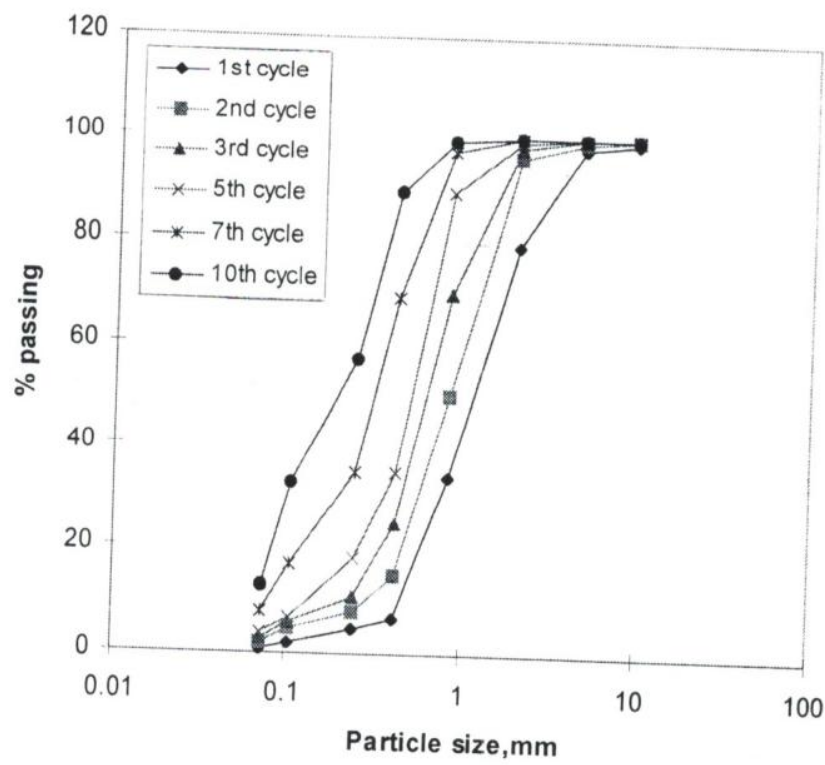

Fig. 7a: Particle size distribution curves for different slaking cycles, Nigorisawa.

In both the cases, it is found that as the number of cycles increases the size of particles become finer and finer. However, in Nigorisawa, the distribution of various sized particle in the $1^{\text {st }}$ cycle is wide. Moreover, the shape of particle size distribution of samples from Nigorisawa shows that the slaking pattern is different in various cycles with that of the samples from Matsunoyama. Again, the largest particle size in the case of Matsunoyama is $38.1 \mathrm{~mm}$ where as it is 9.52 $\mathrm{mm}$ in the case of Nigorisawa. The percentage of finer particles $(0.074 \mathrm{~mm})$ in Matsunoyama is $21 \%$, which is $8 \%$ higher than for Nigorisawa sample. This shows that the sample from Nigorisawa is less weathered than from Matsunoyama.

Fig. 8a and b show the percentage of material passing through two specific sieve sizes (i.e. $9.52 \mathrm{~mm}$ and $2.0 \mathrm{~mm}$ ) as dependent on the number of drying and wetting cycles. In Nigorisawa, the percentage of soil passing through $9.52 \mathrm{~mm}$ sieve in $2^{\text {nd }}$ cycle comes to $96 \%$. Likewise, $96 \%$ of the particles 


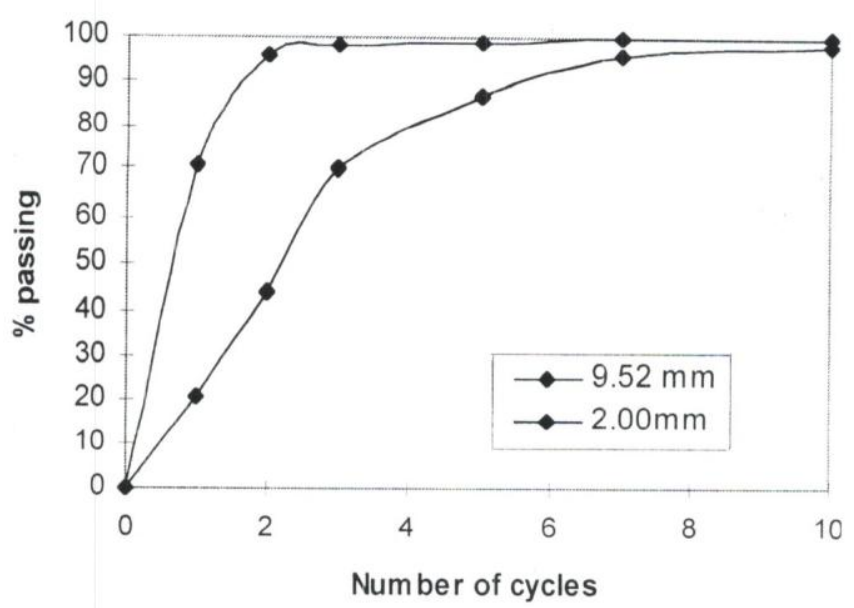

Fig. 8a: Amount of the soil passing through $9.52 \mathrm{~mm}$ and $2 \mathrm{~mm}$ sieve, Nigorisawa.

pass through the $2 \mathrm{~mm}$ sieve in the $7^{\text {th }}$ cycle. Almost all of the samples pass through $9.52 \mathrm{~mm}$ sieve after the $10^{\text {th }}$ cycle. However, the pattern is different from Matsunoyama. This shows that slaking and weathering of sample depends on the type of rock. Different types of mudstone have different tendencies of slaking. Various factors like the content of clay fraction, mineralogical composition, water content and so on affect the shear strength of mudstone.

\section{CONCLUSION}

Test results show that the slaking of mudstones taken from the zone of foundation failure is very high even in a smaller number of cycles. This was the main reason for foundation failure. The main reason for slaking seems to be due to large differences in water content of the mudstone during various periods of the year and frequent drying and wetting of the mudstone. The slaking was higher and faster near the surface. Also, in the case of Nigorisawa and Matsunoyama, the foundation was not fully anchored in

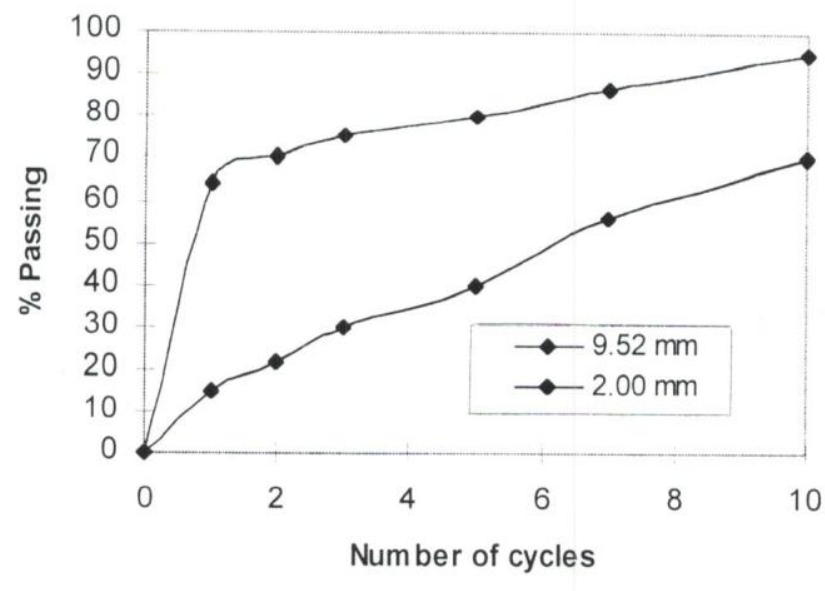

Fig. 8b: Amount of the soil passing through $9.52 \mathrm{~mm}$ and $2 \mathrm{~mm}$ sieve, Matsunoyama.

the rock as slaking progressed beyond the depth of anchorage. Thus failure occurred due to decrease in shear strength as a result of slaking. The failure pattern of the foundation was outwards in horizontal direction. The main reason for it was the easy slaking of the material near surface. Once the foundation moved, the rainwater and snow-melt water entered the cracks. This increased the slaking and decreased the soil strength. To defend this type of foundation failure problem, the depth of anchorage must be greater than the depth affected by slaking.

\section{REFERENCES}

Aoyama, K., Ogawa, S.. and Fukuda, M., 1980, Characteristics of soils of Landslide Areas in Niigata Prefecture, Japan. Proc.International Symposium on Landslides, New Delhi. v. 1, pp. 129-138.

Tiwari, B. and Marui, H., 1999, Sliding Mechanism of Okimi Landslide and Analysis of Overall Blocks. Annual Report of Research Institute of Hazards in Snowy Areas, Niigata University, No. 21, pp. 1-21. 